\section{Parasitic cysts in wild boars hunted in Central Italy: The sanitary controls in the wild game meats chain}

\author{
Alberto Olivastri, ${ }^{1}$ Barbara Paoletti, \\ Carlotta Lauteri, ${ }^{2}$ Luca Pennisi, ${ }^{2}$ \\ Domenico Paludi, ${ }^{2}$ Anna Rita Festino, ${ }^{2}$ \\ AlbertoVergara ${ }^{2}$ \\ ${ }^{1}$ ASUR Marche Area Vasta 5 Ascoli \\ Piceno/San Benedetto del Tronto; \\ ${ }^{2}$ Faculty of Veterinary Medicine, \\ University of Teramo, Italy
}

\begin{abstract}
Seven hundred sixty-five (765) adult wild boars were examined during the 2016/2017 hunting season for the research of parasites. Post mortem inspection was carried out at the slaughterhouse by the Official Veterinarian on the plucks (heart, tongue, lungs, diaphragm, and liver) of the killed animals presented by hunters. Of these, $0.8 \%(6 / 765)$ were positive for Echinococcus granulosus sensu lato (s.1.), and $2.6 \%(20 / 765)$ were positive for the metacestode stage of Taenia hydatigena (Cysticercus tenuicollis), while 0.5\% (4/765) animals showed a mixed infection (Echinococcus granulosus s.l. and Taenia hydatigena). Sixty-three (63) cystic lesions were found. Of these $25,4 \%$ (16/63) were caused by Echinococcus granulosus s.l. and $74,6 \%$ (47/63) were caused by Cysticercus tenuicollis. The more involved organs were liver and lungs, in a less extension omentum and diaphragm. Parasitological analyses showed an overall prevalence of $3.9 \%$ for metacestodes in the hunted animals examined (Paoletti et al., 2018). Hydatids were molecularly characterized as E. granulosus sensu stricto. Trichinella spp. examination results showed no evidences of parasitic cysts. The products of hunting used for own consumption and direct sale to the final consumer or retailer, according to Regulation (EC) No 853/2004, lack of overall control by the Competent Authority. This is a critical point in the food chain of the game meat. The data obtained show the importance of the post mortem inspection and the central role of the Competent Authority to ensure not only the food safety of game meat but also to collect data for extensive epidemiological investigations on live-stocks wildlife settings having a direct impact on public health.
\end{abstract}

\section{Introduction}

Hunting was born as a primary source of nutrition at the beginning of human evolution. Nowadays it has evolved into a recreational activity with substantial commercial interests (Giuggioli et al., 2017). The use of game meats belongs to the cultural and culinary tradition of our country, and nowadays it recognizes a growing interest due to their sensory and nutritional characteristics. In this context, the hunting of large ungulates has a primary role. The rural abandonment and the concentration of activities in few areas have allowed for the re-establishment of bush and wooded areas, representing the ideal habitat of species like wild boar, whose numbers increase exponentially all over the country. Wild boars have been responsible from 2005 to 2009 of the $85 \%$ of agricultural damages (i.e., crop damages) and they are vectors of zoonotic diseases (Rossi et al., 2015). As a consequence, wild boar can be the reservoir and the vector of viruses, bacteria, and parasites having an impact on human health. The consumption of raw or inadequately cooked boar meats consequently could represent a risk. Echinococcus granulosus sensu lato (s.1.) and Taenia hydatigena are worldwide parasites; they have a different biotic potential (i.e., number of proglottids and eggs released) but similar lifecycle (Torgerson et al., 1998; Gemmel et al., 1987).

Echinococcosis is a worldwide zoonotic disease caused by the adult stage of Echinococcus granulosus. Definitive hosts are dogs and other canids; the adult stage resides in their small intestine. Infectious eggs are spread in the environment by the feces of the definitive hosts; intermediate hosts (sheep in the domestic cycle and wild boars in the wild cycle), living in contaminated areas, can be infested. In the wild cycle, the boar has a central role as intermediate host: after ingestion, the egg hatches in the small bowel and releases an oncosphere that penetrates the intestinal wall and migrates through the circulatory system into various organs, especially the liver, less frequently lungs and occasionally kidney, spleen, peritoneal cavity, muscles and very rarely heart and brain. In these organs, the oncosphere develops into a cyst that enlarges gradually. Humans are aberrant intermediate hosts and become infected by ingesting eggs (McManus et al., 2003).

Cysticercosis is a parasite disease caused by the larval stage of the flatworms belonging to the genus Taenia. Cysticercus tenuicollis is the larval form of Taenia hydatigena; the human species has no receptivity to Taenia hydatigena larval and adult forms. Definitive hosts are dogs and wild canids (i.e., foxes), while intermediate hosts are cattle, sheep, and equines. Little information is available on wild boar (Paoletti et al., 2018). The adult stage resides in the definitive host intestine and
Correspondence: Alberto Vergara, Faculty of Veterinary Medicine, University of Teramo, Campus Universitario "Aurelio Saliceti, Via Renato Balzarini 1, 64100 Teramo (TE), Italy. E-mail: avergara@unite.it

Key words: Wild boar meats, food safety, public health, parasites.

Conflict of interest: The authors declare no conflict of interest.

Contributions: The authors contributed equally.

Funding: None

Ethics approval and consent to participate: This research was conducted in accordance with all relevant guidelines and procedures.

Received for publication: 5 October 2020.

Revision received: 30 December 2020.

Accepted for publication: 22 March 2021.

This work is licensed under a Creative Commons Attribution-NonCommercial 4.0 International License (CC BY-NC 4.0).

(C) Copyright: the Author(s), 2021

Licensee PAGEPress, Italy

Italian Journal of Food Safety 2021; 10:9383

doi:10.4081/ijfs.2021.9383

releases the infectious eggs throughout the feces. Intermediate hosts are infected by ingesting the eggs present in the environment. Once ingested, the young larvae hatch out of the eggs in the gut, cross the intestinal wall, reach the bloodstream and migrate to the liver via the portal vein. Once in the liver, larval forms migrate through the organ and, oriented by a superficial tropism, gain the Glisson's subcapsular surface where they develop cystic lesions. With a similar mechanism they can origin cystic lesions in other abdominal organs. Furthermore, larval forms migration (larva migrans) causes lesions in organs, characterized by necrosis, acute and chronic inflammation and fibrosis. Cysticercoides (Cysticercus spp. larval form) are found mainly in the liver, in the omentum, and the mesentery, often on the surface of various abdominal organs.

Although the human species has no receptivity to Taenia hydatigena and its larval form (Cysticercus tenuicollis), there is another parasite ascribed to Cestoda which can causes cysticercosis in humans: Cysticercus cellulosae, the larval form of Taenia solium. The definitive host is the human species, while the intermediate hosts are wild and domestic suids. However, from a parasitological and ecological point of view, the human species can also represent an "aberrant" intermediate host, infected by 
fecal-oral ingestion of parasite eggs released by adult worm proglottids in human feces (Centers for Disease Control and Prevention). From this point of view, the ingestion of food, including meats, contaminated with feces containing eggs or proglottids may potentially represents the first event to the human cysticercosis pathogenesis.

The present study focuses on the post mortem inspection of plucks (heart, tongue, lungs, diaphragm, and liver) performed at the slaughterhouse by the Official Veterinarian to evaluate the presence of parasitic cysts in wild boars hunted in Central Apennines, in the province of Ascoli Piceno. Laws concerning the use of large wild game meat intended for human consumption are numerous and complex, since they condensate health aspects with wildlife management and hunting normative. The results obtained are discussed focusing on the role of the Competent Authority in wild game meat chain, highlighting its critical aspects, to ensure the highest level of food safety and to guarantee public health.

\section{Materials and methods}

The study was carried out on seven hundred sixty-five (765) adult boars killed for self-consumption and for commercial purposes during the hunting season 2016/2017 in Marche region, Central Italy (Figure 1). The geographic area covered by this study includes two National Park areas: Monti Sibillini and Gran Sasso-Monti della Laga National Parks.

According to the Italian regional (Marche) law, hunters must present the pluck (heart, tongue, lungs, diaphragm, and liver) to the Veterinary Service for Trichinella spp. examination (Regulation EC No 1375/2015) and post mortem inspection (Regulation EC No 854/2004). Post mortem inspection was carried out at the slaughterhouse by the Official Veterinarian, the Competent Authority. The pluck of each boar was carefully examined for the presence and location of cysts of parasites by visual inspection, palpation, and systematic dissection. For each organ, the number and the location of the cysts were recorded.

All infected organs were removed and transported to the Faculty of Veterinary Medicine of Teramo (Italy) for parasitological analysis (Paoletti et al., 2018). For each organ, the number and the location of the cysts were recorded. Hydatid cysts, when found, were ranked as fertile, sterile, or calcified/caseous, as described elsewhere (Varcasia et al., 2006). Hydatid fertility was assessed after dissection and collection of the germinal layer to verify the presence and vitality of protoscoleces through flame cell activity and motility by light microscopy without staining (Scala et al., 2006).

DNA was then extracted from the germinal layer and protoscoleces from single fertile and sterile cysts, using a genomic DNA extraction kit (QIAamp DNA Mini Kit, QIAGEN GmbH, Germany) according to manufacturer's instructions.

About 10-20 ng of template DNA was used to amplify a fragment within the cytochrome c oxidase subunit 1 (COX1) and the NADH dehydrogenase subunit 1 (ND1) mitochondrial genes following protocols published by Bowles et al., 1992 and Bowles and McManus, 1993. PCR products were commercially sequenced by MWGBiotech (Ebersberg, Germany). The nucleotide sequences generated were edited in Proseq 3.5 (Filatov, 2002) and compared with those available in the National Center for Biotechnology Information (NCBI) database using the basic local alignment search tool (BLAST).

\section{Results}

The results of the post mortem inspection carried out by the Official Veterinarian on the 765 wild boar plucks collected during hunting season 2016/2017 are shown in Table 1.

The post mortem inspection located cystic lesions in the $3.9 \%(30 / 765)$ of wild boars; in the $0.8 \%$ of animals they were caused by Echinococcus granulosus s.l. $(6 / 765)$, in the $2.6 \%$ by Cysticercus tenuicollis $(20 / 765)$ while in the $0.5 \%$ of boars $(4 / 765)$ there was a mixed infection
(Echinococcus granulosus s.l. and Cysticercus tenuicollis). Sixty-three (63) cystic lesions were found in total. Of these $25.4 \% \quad(16 / 63)$ were caused by Echinococcus granulosus s.l. and $74.6 \%$ (47/63) by Cysticercus tenuicollis. For both parasites, the more involved organs were liver and lungs, in a less extension omentum and diaphragm.

Parasitological analyses showed an overall prevalence of $3.9 \%$ for metacestodes in the hunted animals examined (Paoletti et al., 2018).

A total of 16 hydatids were found, of which $12.5 \%$ were fertile, $37.5 \%$ were sterile, $31.3 \%$ were caseous, and $18.8 \%$ were calcified. All cysticerci found were viable with their characteristic bottleneck morphology. Eight hydatids (two fertile and six sterile cysts) were molecularly characterized as E. granulosus sensu stricto, showing $100 \%$ identity with GenBank accession numbers KT2002231.1 and KY76689.1 from E. granulosus sensu stricto (former genotype G1).

Trichinella spp. examination results showed no evidences of parasitic cysts.

\section{Discussion}

This study highlights presence of Echinococcus granulosus s.l and Taenia hydatigena in the wild boar population of the tested area, with higher incidence where pastoral activity was more widespread. Cystic echinococcosis represents a major public health concern worldwide and it is currently considered among the five most common zoonosis in the Mediterranean area (Varcasia et al., 2011; Paoletti et al.,

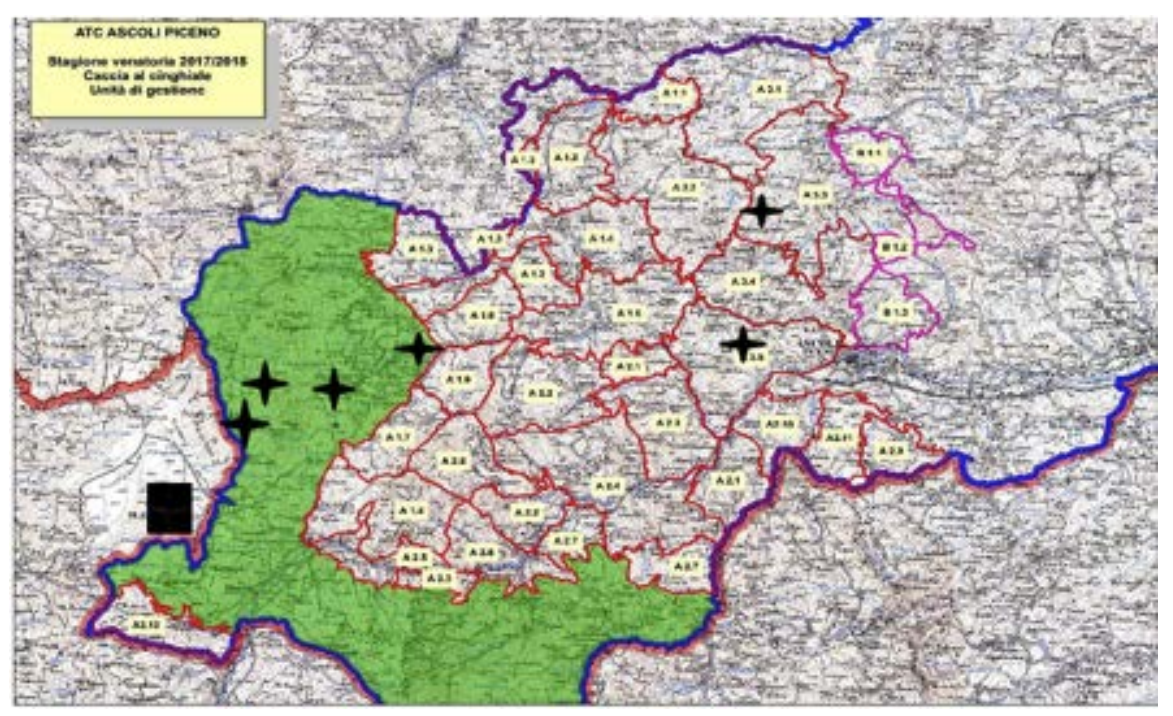

Figure 1. Study setting. 
2018). Monitoring activities carried out in the European countries showed a high prevalence of Echinococcus (EFSA, 2018). The European Union One Health 2018 zoonoses Report dedicates a section on the surveillance and monitoring of cystic and alveolar echinococcosis in humans and animals. In 2018 the highest number of animals infected with E. granulosus s.l. was reported in Bulgaria, Spain, Greece, Poland and Italy and mainly observed in small ruminants (EFSA and ECDC, 2019). Surveillance of E. granulosus s.l. is usually carried out on livestock intermediate hosts during slaughterhouse inspection. In particular, necroscopy on sheep liver and lungs is used to detect the presence of parasitic cysts. Wild boars are intermediate hosts of E. granulosus s.l. and are likely to be involved in the epidemiology of the parasite in its sylvatic cycle (Di Paolo et al., 2017; Paoletti et al., 2018). Despite the wide distribution of wild boar populations in Italy (Toso and Pedrotti, 2001), few studies evaluated the presence of E. granulosus in wild boars (Di Paolo et al., 2017; Paoletti et al., 2018). T. hydatigena metacestodes were found with a high prevalence compared with cystic Echinococcus, but the worldwide distribution of both parasites and the fact that they have the similar lifecycle suggests that wild boars positive to cysticercosis living in contaminated areas could have a greater risk of exposure to cystic echinococcosis compared with other animals (Paoletti et al., 2018), also bearing in mind that cystic echinococcosis develops slowly and relatively recent cystic lesions may not be visible, especially in young animals (Scala et al., 2016; Varcasia et al., 2004). More extensive epidemiological investigations to determine causal factors, economic impact, and public health importance of the zoonosis caused by parasites in wild boar populations are needed. Processing centers, sectioning centers, or slaughterhouses approved following Regulation (EC) No 853/2004 have a central role in these surveys; wild game meat is subjected to Sanitary Inspection by an Official Veterinarian and, if approved, submitted to the market. According to Regulation (EC) No 853/2004, Subparagraph 3, Section 4, Chapter 2, this way is followed only by the products of hunting used for marketing. Regulation (EC) No 853/2004 exempts hunters from using wild game for own consumption or supplying small quantities of the wild game directly to the final consumer or the local retailers. The legislation, at any levels, does not elect an Institutional Figure to guarantee the safety of the products of hunting used for own consumption and direct sale to the final consumer or retail and defers the final product warranty to the hunter, who is responsible for the safety of the product. According to the law, he is a trained person having sufficient knowledge about diseases of the game to correctly identify these at the scene of the hunt (Regulation EC No $853 / 2004$, Section 4, Chapter 1, points 1 to 5 ). The lack of overall control of the production chain by a Competent Authority raises sanitary issues. Legislation attributes to hunter the juridical responsibility for the safety of wild game meats and its derived products. In relation to this and to the high specialization grade needed to acquire this competence, it represents another critical

point in wild game meats chain. From a parasitological and ecological point of view, the human species represents for Echinococcus granulosus s.l. an "aberrant" intermediate host, uniquely infected by ingesting parasite eggs from canids, the definitive hosts (Centers for Disease Control and Prevention), and has no receptivity to Taenia hydatigena larval and adult forms.

The cysts of Echinococcus granulosus s.l. and Cysticercus tenuicollis, the metacestode of Taenia hydatigena, in relation to their biological cycles, do not represent a

Table 1. Results of the post mortem inspection.

\begin{tabular}{|c|c|c|c|}
\hline Viscera \# & Cystic lesion & N. of lesions & Localization \\
\hline 1 & $\begin{array}{l}\text { Cysticercus } \\
\text { Hydatid }\end{array}$ & $\begin{array}{l}1 \\
1\end{array}$ & $\begin{array}{l}\text { Omentum } \\
\text { Liver }\end{array}$ \\
\hline 2 & Cysticercus & 1 & Liver \\
\hline 3 & Cysticercus & 1 & Liver \\
\hline 4 & Cysticercus & 3 & Liver \\
\hline 5 & Hydatid & 2 & Lung \\
\hline 6 & Hydatid & 2 & $\begin{array}{l}\text { Lung } \\
\text { Liver }\end{array}$ \\
\hline 7 & Cysticercus & 2 & $\begin{array}{l}\text { Lung } \\
\text { Liver }\end{array}$ \\
\hline 8 & Cysticercus & 1 & Liver \\
\hline 9 & Hydatid & 2 & Lung \\
\hline 10 & Cysticercus & 1 & Omentum \\
\hline 11 & Cysticercus & 2 & Liver \\
\hline 12 & Hydatid & 1 & Liver \\
\hline 13 & Cysticercus & 3 & $\begin{array}{l}\text { Lung (2) } \\
\text { Liver (1) }\end{array}$ \\
\hline 14 & Cysticercus & 2 & Liver \\
\hline 15 & $\begin{array}{l}\text { Hydatid } \\
\text { Cysticercus }\end{array}$ & $\begin{array}{l}1 \\
8\end{array}$ & $\begin{array}{c}\text { Lung } \\
\text { Liver (6) } \\
\text { Omentum (2) }\end{array}$ \\
\hline 16 & Cysticercus & 3 & $\begin{array}{l}\text { Lung (2) } \\
\text { Liver (1) }\end{array}$ \\
\hline 17 & Cysticercus & 1 & Omentum \\
\hline 18 & Hydatid & 1 & Liver \\
\hline 19 & Cysticercus & 1 & Lung \\
\hline 20 & $\begin{array}{c}\text { Hydatid } \\
\text { Cysticercus }\end{array}$ & $\begin{array}{l}2 \\
1\end{array}$ & $\begin{array}{l}\text { Lung } \\
\text { Liver } \\
\text { Lung }\end{array}$ \\
\hline 21 & Cysticercus & 1 & Diaphragm \\
\hline 22 & Cysticercus & 1 & Liver \\
\hline 23 & Cysticercus & 1 & Liver \\
\hline 24 & Cysticercus & 1 & Lung \\
\hline 25 & Hydatid & 2 & Liver \\
\hline 26 & $\begin{array}{c}\text { Hydatid } \\
\text { Cysticercus }\end{array}$ & $\begin{array}{l}2 \\
1\end{array}$ & $\begin{array}{l}\text { Liver } \\
\text { Liver }\end{array}$ \\
\hline 27 & Cisticercus & 1 & Liver \\
\hline 28 & Cysticercus & 2 & Liver \\
\hline 29 & Cysticercus & 2 & Liver \\
\hline 30 & Cysticercus & 6 & Liver \\
\hline
\end{tabular}


direct zoonotic hazard for humans (i.e., consumers). They could rather represent a hygienic and sanitary issues. In fact, the pathogenic potential related to direct contact with cysts of Echinococcus granulosus s.l. and Cysticercus tenuicollis is ascrivible to hypersensibility type I mechanisms related to the presence in humans of speciesspecific or crossreactive parasite's antigens antibodies, with special regards to $\mathrm{IgE}$, potentially causing anaphylaxis.

\section{Conclusions}

The relationship between the human and other animal species represents a fascinating ecological symphony of dynamic and mutual interactions composed by the evolution.

The evolutionary drawing is represented by the interactions of three main actors: animal species, genes and environment. This results in a co-evolution between species, humans included, characterized by ecological complex relationship, such as parasitism.

Many parasites species had evolved their biological cycles in a close relationship with the human species, resulting in different levels of parasitism. In function of parasites tropism, for example, the human species may represent a definitive host, such as for Trichinella spp., Taenia solium and $T$. saginata.

In other cases, the domestication process catalyzed a close relationship between humans and domestic species, such as i.e., Echinococcus granulosus, in which humans represents an "aberrant" intermediate host, while domestic and wild canids act as definitive host.

For other parasites (i.e., Taenia hydatigena), the human species shows no receptivity, linking their cycles to domestic animal species.

From this point of view these parasites may represent a sanitary or medical issue for the human species. According to this, health law corpus (i.e., Trichinella spp. examination legislated by Regulation EC No $1375 / 2015$ and post mortem inspection by Regulation EC No 625/2017) is strictly intertwined to bioecological, social and antropological aspects.

In this context, hunting and consumption of meats of wild large ungulates have notable importance. In particular, inspective different procedures led to different possibilities of control and monitoring of parasites in wild boars hunted and, definitely, to different levels of food safety. Furthermore, they minimize the transmission to humans of potential zoonotic agents (i.e., Neospora caninum, Toxoplasma gondii and Sarcocystis spp.), (Katarína Reiterová et al.,
2016). Our study focuses on detection in wild boars of Trichinella spp., Echinococcus granulosus and Taenia hydatigena (Cysticercus tenuicollis), studying three different species related to humans by different parasitism levels (with the exception for Taenia hydatigena). The study interpole several different aspects: from anatomopathological to juridical point of view, demonstrating the importance of a multidisciplinary approach to these medical and sanitary issues.

The adoption of appropriate control procedures and specific protocols even in the cases of the products of hunting used for own consumption and direct sale to the final consumer or retail, as well as ensuring the safety in all the links of the game meat chain, would also be able to provide useful insights for health surveillance of wildlife animal population.

\section{References}

Atanassova V, Apelt J, Reich F, Klein G, 2008. Microbiological quality of the freshly shot game in Germany. Meat Sci 78: 414-19.

Boadella M, Vincente J, Ruiz-Fons F, de la Fuerte J, Gortàzar C, 2012. Effects of culling Eurasian wild boar (Sus scrofa) on the prevalence of Mycobacterium bovis and Aujesky disease virus". PrevVet Med 107: 214-221.

Boadella M., Ruiz-Fons F, Vincente J, Martin M, Segales J, Gortàzar C, 2011. Seroprevalence Evolution of Selected Pathogens in Iberian Wild Boar. Transbound emerg dis 1: 1-10.

Bowles J, Blair D, McManus DP, 1992. Genetic variants within the genus Echinococcus identified by mitochondrial DNA sequencing. Mol Biochem Parasitol 54: 165-73.

Bowles J, McManus DP, 1993. NADH dehydrogenase 1 gene sequences compared for species and strains of the genus Echinococcus. Int J Parasitol 23: 969-72.

Cavallini P\& P, Banti 1999. I danni causati dal cinghiale e dagli ungulati alle colture agricole. Stima e prevenzione Quaderno ARSIA Firenze IT.

Centers for Disease Control and Prevention (CDC), Cysticercosis. Available from: https://www.cdc.gov/parasites/cysticercosis/biology.html .

Centers for Disease Control and Prevention (CDC), Echinococcosis. Available from: https://www.cdc.gov/ parasites/echinococcosis/biology.html .

Dakkak A, 2010. Echinococcosis/hydatidosis: a severe threat in Mediterranean countries. Vet Parassitol 24: 2-11.

Di Paolo A, Piseddu T, Sebastianelli M,
Manuali E, Corneli S, Paniccì M, Papa P, Viali S, Mazzone P, 2017. Detection of Echinococcus granulosus G3 in a wild boar (Sus scrofa) in Central Italy using PCR and sequencing. J Wildl Dis 53: 399-401.

Eckert J, Gemmell MA, Meslin JX, Pawłowski ZS, 2001. Manual on Echinococcosis in Humans and Animals: a Public Health Problem of Global Concern OIE.

European Commission, 2002. Regulation on the European Parlament and of the Council of 28 January laying down the general principles and requirements of food law, establishing the European Food Safety Authority and laying down procedures in matters of food safety,178/2002/CE. In: Official Journal, L $31 / 1,1 / 2 / 02$.

European Commission, 2002. Regulation on the European Parlament and of the Council of 28 January laying down the general principles and requirements of food law, establishing the European Food Safety Authority and laying down procedures in matters of food safety,178/2002/CE. In: Official Journal, L $31 / 1,1 / 2 / 02$.

European Commission, 2004. Regulation on the European Parlament and of the Council of 29 April 2004 laying down specific hygiene rules for food of animal origin ,853/2004/CE. In: Official Journal, L 139/55, 30/4/04.

European Commission, 2005. Regulation on the European Parlament and of the Council of 15 November 2005 laying down microbiological criteria for foodstuffs, 2073/2005/CE. In: Official Journal, L 338/1, 22/12/05.

European Commission, 2009. Regulation on the European Parlament and of the Council of 21 October 2009 laying down health rules as regards animal byproducts and derived products not intended for human consumption and repealing Regulation (EC) No 1774/2002 (Animal by-products Regulation),1069/2002/CE. In: Official Journal, L 300/1, 14/11/09.

European Commission, 2014. Regulation on the European Parlament and of the Council of 13 June 2014 amending Annex III to Regulation (EC) No 853/2004 of the European Parliament and of the Council and Annex I to Regulation (EC) No 854/2004 of the European Parliament and of the Council as regards the specific requirements for handling large wild game and for the post-mortem inspection of wild game,633/2014/CE. In: Official Journal, L 175/6, 14/06/14.

European Commission, 2014. Regulation on the European Parlament and of the 
Council of 13 June 2014 on a model certificate for the trade of unskinned large wild game,636/2014/CE. In: Official Journal, L 175/6, 14/06/14.

European Commission, 2015. Regulation on the European Parlament and of the Council of 10 August 2015 laying down specific rules on official controls for Trichinella in meat,1375/2015/CE. In: Official Journal, L 212/7, 11/08/15.

European Commission, 2017. Regulation on the European Parlament and of the Council of 15 March 2017 on official controls and other official activities performed to ensure the application of food and feed law, rules on animal health and welfare, plant health and plant protection products, 625/2017/CE. In: Official Journal, L 95/1, 7/04/17.

Filatov DA, 2002. PROSEQ: a software for preparation and evolutionary analysis of DNA sequence data sets Mol Ecol Notes 2: 621-4.

Garippa G, 2006. Updates on Cystic Echinococcosis (CE) in Italy. Parassitologia 48: 57-9.

Garippa G, Varcasia A, Scala A, 2004. Cystic echinococcosis in Italy from the 1950 s to present. Parassitologia 46: 387-91.

Gemmell M, Lawson JR, Roberts M, 1987. Population dynamics in echinococcosis and cysticercosis: evaluation of the biological parameters of Taenia hydatigena and $T$. ovis and comparison with those of Echinococcus granulosus.
Parasitology 94: 161-80.

Giuggioli G, Olivastri A, Pennisi L, Paludi D, Ianieri A, Vergara A, 2017. The hygiene-sanitary control in the wild game meats. Italian Journal of Food Safety 6: 6875 .

Koutsoumanis K, Allende A, AlvarezOrdonez A, Bolton D, Bover-Cid S, Chemaly M, Davies R, Di Cesare A, Herman L, Hilbert F, Lindqvist R, Nauta M, Peixe L, Ru G, Simmons M, Skandamis P, Suffredini E, Caccio S, Chalmers R, Deplazes P, Devleesschauwer P, Innes E, Romig T, van der Giessen J, Hempen M, Van der Stede and Robertson L, 2018. Public health risks associated with food-borne parasites. Efsa j. 25 October 2018.

McManus DP, Zhang W, Li J, Bartley PB, 2003. Echinococcosis. Lancet 362: 1295-304.

Miller JE, Ray M, Kaplan G,2012. Sheep and Goats medicine. 2nd ed. Pugh D.G Waverly, Alabama, USA.

Paoletti B, Della Salda L, Di Cesare A, Iorio R, Vergara A, Fava C, Olivastri A, Dessì G, Scala A, Varcasia A, 2018. Epidemiological survey on cystic echinococcosis in wild boar from Central Italy . Parassitol. Res 118: 43-6.

Reiterová K, Špilovská S, Blaňarová L, Derdáková M, Čobádiová A, Hisira V, 2016. Wild boar (Sus scrofa) - reservoir host of Toxoplasma gondii, Neospora caninum and Anaplasma phagocytophilum in Slovakia. Acta Parasitol 61:
255-60.

Rossi S, Staubach C, Blome S, Guberti V, Thulke H, Vos A, Koenen F, Le Potier $\mathrm{M}$, 2015. Controlling of CSFV in European wild boar using oral vaccination: A review. Front in Microb 6: 2-11

Scala A, Urrai G, Varcasia A, Nicolussi P, Mulas M, Goddi L, Pipia AP, Sanna G, Genchi M, Bandino E (2016) Acute visceral cysticercosis by Taenia hydatige$n a$ in lambs and treatment with praziquantel. J Helminthol 90: 113-6.

Torgerson P, Williams D, Abo-Shehada M,1998. Modelling the prevalence of Echinococcus and Taenia species in small ruminants of different ages in northern Jordan. Vet Parasitol 79: 3551.

Toso S, Pedrotti L, 2001. Linee guida per la gestione del cinghiale (Sus scrofa) nelle aree protette Quad. Cons.Natura, 2, Min. Ambiente - Ist. Naz. Fauna Selvatica (In Italian).

Varcasia A, Canu S, Lightowlers MW, Scala G, Garippa G,2006. Molecular characterization of Echinococcus granulosus strains in Sardinia. Parassitol Res 98: 273-7.

Varcasia A, Canu S, Kogcos A, Pipia AP, Scala A, Garippa G, Seimenis A, 2007. Molecular characterization of Echinococcus granulosus in sheep and goats of Peloponnesus, Greece. Parassitol Res 101: 1135-9. 